\title{
Entre o empenho, o acolhimento e a impotência: dilemas de agentes comunitárias de saúde na produçáo do cuidado e da humanização ${ }^{1}$
}

\author{
Renata Bellenzania ${ }^{a}$, Rúbia de Fátima Mendes ${ }^{b}$ \\ ${ }^{a}$ Docente, Curso de Psicologia, Universidade Federal de Mato Grosso do Sul - UFMS, Paranaíba, MS, Brasil

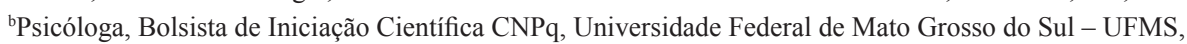 \\ Paranaíba, MS, Brasil
}

\begin{abstract}
Resumo: A Estratégia Saúde da Família amplia o modelo médico-centrado para o de equipe. A dimensão das relações intersubjetivas dos agentes de saúde com usuários é valorizada pela Política Nacional de Humanização, para qualificar o cuidado e produzir saúde com integralidade. Por meio de 6 grupos focais, foram exploradas as práticas e as concepções de 40 agentes sobre o engajamento pessoal e coletivo no cuidado humanizado, em seis unidades de um município em Mato Grosso do Sul-BR. As análises das conversações evidenciaram oscilações entre empenho e impotência dos agentes ao não conseguirem proporcionar cuidados plenos, principalmente quando se demandavam técnicas, procedimentos e coordenação de ações pela gestão e intersetoriais. A efetivação da PNH, transversal à Saúde da Família, é indissociável da qualidade local do SUS; essa afeta as possibilidades reais da humanização, da sustentabilidade do engajamento dos agentes no acolhimento e os planos: subjetivo e intersubjetivo do trabalho em saúde. Gestores devem acolher percepções e expressões de impotência e frustração dos agentes, tomando-as como expressivos, também, de problemas estruturais e de processo a serem manejados.

Palavras-chave: Agentes Comunitários de Saúde, Humanização da Assistência, Acolhimento, Saúde do Trabalhador.
\end{abstract}

\section{Effort, reception and impotence: dilemmas of community health workers in care and humanization}

\begin{abstract}
The "Family Health" Strategy (Estratégia de Saúde da Família) extends the doctor-centered model to the team model. Conversations between health workers and users are valued by the National Policy of Humanization (Plano Nacional de Humanização - PNH). The practices and concepts of 41 agents on personal and collective engagement in humanized care were investigated in six health services in a municipality in the State of Mato Grosso do Sul. The content analysis showed that agents oscillate between effort and impotence, because they cannot provide full care to patients, especially when techniques, procedures, and coordination of actions by the management are demanded. The implementation of the National Policy of Humanization, cross-sectional to the "Family Health" Strategy, is fundamental to the local quality of the Public Health Service (SUS); it affects the real possibilities of humanization, the sustainability of agents' engagement in care, and the health service subjectivity. Managers must care about the perceptions and expressions of helplessness and frustration from workers, taking them as indicative of structural and process problems that should to be managed.
\end{abstract}

Keywords: Community Health Workers, Humanization of Assistance, User Embracement, Occupational Health. 


\section{Introdução}

\subsection{A Estratégia Saúde da Família: o trabalho do agente comunitário de saúde e as interfaces com a Política Nacional de Humanização (PNH)}

Desde meados da década de 1990, a Estratégia de Saúde da Família (ESF) constitui o modelo para efetivar a reorganização da Atenção Básica em Saúde (AB) no País, no cenário da implantação da Política Nacional de Saúde a partir do Sistema Único de Saúde (SUS), iniciado em fins de 1980 (BRASIL, 2006a). A $\mathrm{AB}$ caracteriza-se por um conjunto de açóes de saúde que abrange a promoção e a proteção da saúde, a prevenção de agravos, o diagnóstico, o tratamento, a reabilitação e a manutenção da saúde. Seus princípios são: universalidade; acessibilidade; coordenaçáo do cuidado, do vínculo e sua continuidade; integralidade; corresponsabilização; humanização; equidade e participação social (BRASIL, 2006a).

A Estratégia de Saúde da Família, por sua vez, deve: 1) ter caráter substitutivo em relação ao modelo de atendimento historicamente em vigor nos centros de saúde até a década de 1990, altamente centrados no trabalho médico e não em uma equipe; 2) desenvolver açóes territoriais; 3) manter continuamente uma postura pró-ativa frente aos problemas de saúde-doença da população; 4) desenvolver atividades com base em planejamento e diagnóstico situacional, tendo como foco a família e a comunidade; 5) buscar a integração com instituiçôes e organizaçóes sociais, a fim do desenvolvimento de parcerias; e também ser um espaço de construçáo de cidadania (BRASIL, 2006a).

Além dos agentes, a equipe mínima de saúde da família é constituída por médico, enfermeiro, dentista e auxiliares de enfermagem. As atribuiçóes dos agentes relacionam-se a um aspecto estruturante: o papel de educadores e agentes de mudança na comunidade em que vivem (BRASIL, 2006a). Geralmente residem na comunidade em que trabalham e, também, não lhes é exigida a conclusão de nenhum curso específico em saúde (NUNES et al., 2002 apud PUPIM, 2008; LIMA; MOURA, 2005). Seu potencial transformador está, principalmente, no fato de realizar continuamente as visitas domiciliares, conhecendo as reais necessidades da comunidade e fazendo a mediação desta com a equipe, e com o sistema de saúde (BRASIL, 2006a).
Acompanhando a crescente valorização dessa categoria profissional nas propostas do Ministério da Saúde, tem crescido o número de estudos sobre a dimensão intersubjetiva do trabalho realizado pelos agentes de saúde e suas implicaçóes. Segundo Lunardelo (2004), seu papel adicional de anteparo do sistema de saúde o coloca em condição de lidar, por vezes, com as resistências da população, enfrentando dificuldades de relacionamento. O domicílio não é um território público e o seu acesso nem sempre é evidente e fácil; portanto, para realizar seu trabalho, o agente deve estabelecer vínculo e relaçôes de confiança com a comunidade, devendo preservar a privacidade familiar.

Jardim (2007) destaca os prejuízos em relação à imagem do agente diante da comunidade - nas situações em que as demandas da população são superiores à disponibilidade dos recursos e serviços. Ocorreria, assim, a potencialização do sofrimento vivenciado pelo profissional e seu constrangimento pelas dificuldades em relaçáo ao cumprimento do trabalho. A expectativa social de que o agente dê respostas positivas às dores, medos, dúvidas, angústias e aos riscos de morte vivenciados por usuários gera uma grande pressáo no cotidiano de seu trabalho e acarreta, por vezes, um intenso sofrimento psíquico dos profissionais.

Açóes de suporte ao trabalho dos agentes e a educação permanente da categoria são preconizadas pela Política Nacional de Atenção Básica que valoriza, também, a necessidade de gestores conhecerem outros aspectos das vidas desses profissionais. Deve se levar em consideração a pessoa do agente, seus dilemas, dificuldades e realizaçóes, fatores estes influenciados ou náo pela natureza peculiar do seu trabalho (BRASIL, 2006a). A valorização da subjetividade e da pessoalidade desse profissional tem se destacado, também, no escopo das diretrizes da Política Nacional de Humanização da Atenção e Gestão no SUS (PNH), cujo dispositivo técnico e filosófico central é o chamado acolhimento.

$\mathrm{O}$ acolhimento deve ser compreendido segundo diferentes, entretanto, complementares perspectivas, tais como: 1) postura humana de reconhecimento e compromisso com "o outro", expressa em atitudes de dar acolhida, admitir, aceitar, dar ouvidos, dar crédito, receber, atender (FERREIRA, 1975), enfim, "estar com" ou "perto de", tanto do ponto de vista da gestão para com seus cidadãos trabalhadores, como do ponto de vista desses mesmos trabalhadores quando se colocam diante dos usuários; 2) modo "mais humanizado" de operar o trabalho da atenção e da gestáo ao se organizar a assistência à saúde, valorizando seu caráter coletivo e cooperativo, assim 
como a necessidade de diálogo e de construção de vínculo qualificado entre trabalhadores e gestores, e entre trabalhadores e usuários, a fim de se garantir o acesso ao cuidado com resolutividade (BRASIL, 2006b). A PNH pretende lidar:

[...] com as dificuldades de acesso dos usuários aos serviços [...] o incentivo a formas de acolhimento que levem à otimização dos serviços e ao acesso dos usuários a todos os níveis de atenção do sistema de saúde, com mecanismos de referência e contrarreferência. (FORTES, 2004, p. 33).

$\mathrm{O}$ acolhimento enquanto diretriz operacional propóe inverter a lógica da organização e do funcionamento do serviço de saúde. (FRANCO; BUENO; MERHY, 1999, p. 347);

seus princípios são:

1) Atender a todas as pessoas que procuram os serviços de saúde, garantindo a acessibilidade.

2) Reorganizar o processo de trabalho, a fim de que este desloque seu eixo central do médico para uma equipe multiprofissional - equipe de acolhimento, que se encarrega da escuta do usuário comprometendo-se a resolver seu problema de saúde. 3) Qualificar a relação trabalhador-usuário, que deve dar-se por parâmetros humanitários, de solidariedade e cidadania. (FRANCO; BUENO; MERHY, 1999, p. 347).

\section{Ademais:}

A proposta do acolhimento, articulada com outras propostas de mudança no processo de trabalho e gestão dos serviços (cogestão, ambiência, clínica ampliada, programa de formação em saúde do trabalhador, direitos dos usuários e ações coletivas) é um dos recursos importantes para a humanização dos serviços de saúde. (BRASIL, 2006b, p. 16).

Desde 2004, com a implantação da PNH, elegeram-se os processos de trabalho e de gestấo como os principais alvos das açóes humanizadoras com as quais se pretende mudar a cultura institucional dos serviços de saúde (BRASIL, 2004; RIOS, 2008). As noçôes de humanização e de acolhimento em seus sentidos mais amplos se expandem, envolvendo não só as preocupaçóes com os usuários, mas também com os trabalhadores por meio da proteção de sua saúde ocupacional e da promoção do bem estar no trabalho. Seriam alvos de mudanças: os modelos de gestão hierarquizados e pouco participativos; as condiçóes inadequadas de trabalho, a pouca valorização dos trabalhadores do SUS, especialmente os não médicos, o trabalho fragmentado e médico-centrado, entre outras. Intensifica-se a compreensão dos serviços enquanto instituiçóes compostas por sujeitos, cuja subjetividade é inerente ao trabalho em saúde; considera-se que, simultaneamente à produçáo do cuidado em saúde, ocorre a produção de Sujeitos pelo trabalho (CAMPOS, 2000).

Com base no exposto, o objetivo do presente trabalho é discutir a respeito da dimensão intersubjetiva do trabalho dos agentes de saúde na interação com usuários, na medida em que suas concepçóes e práticas tendem a se aproximar dos princípios e dispositivos da $\mathrm{PNH}$, especialmente das noçôes de acolhimento, humanização e atenção integral. A dimensão intersubjetiva, no caso dos trabalhadores com quem se realizou o estudo, mostrou-se marcada pela emergência de dilemas cotidianos com os quais os agentes têm que lidar quando ampliam o escopo de suas açóes e se colocam na posiçáo de escuta e de acolhimento de demandas e necessidades. Há implicaçóes relevantes para sua saúde e bem-estar, ao se engajarem numa proposta de atenção integral, no contexto de uma organização ainda frágil dos processos de trabalho e da gestáo municipal da Saúde.

O estudo realizou-se em seis unidades básicas, organizadas segundo a Estratégia Saúde da Família (ESF), de um município com aproximadamente 40 mil habitantes, no interior do Estado de Mato Grosso do Sul.

\section{Método}

A fim de possibilitar a apreensão de conteúdos carregados de sentidos e significados, o procedimento de coleta de dados consistiu na realizaçáo de um grupo focal em cada uma das seis unidades (com um total de 9 equipes da ESF), cujos convidados eram todos os profissionais do serviço ${ }^{2}$. Os grupos focais realizaram-se em 2010. O total de participantes nos grupos focais das 6 unidades analisadas (de todas as categorias profissionais) foi de 54. A maioria era do sexo feminino; 40 eram agentes comunitários ( $74 \%$ do total); os restantes eram: técnicos de enfermagem, enfermeiros e digitadores/recepcionistas. Uma docente conduziu os grupos focais junto com uma acadêmica de psicologia.

Gondim (2002), com base em Morgan (1997), afirma que o grupo focal é uma técnica para coletar dados por meio de conversaçôes e interações intragrupais, ao se discutir um tópico especial sugerido pelo pesquisador. Ocupa uma posição intermediária entre a observação participante e 
as entrevistas em profundidade, sendo útil para compreender o processo de construção das percepçóes, atitudes e representaçôes sociais (VEIGA, GONDIM, 2001 apud GONDIM, 2002). A utilização dos grupos focais para pesquisas em Saúde Pública têm crescido significativamente desde o início da década de 1990, inclusive em pesquisas na Estratégia Saúde da Família (TRAD, 2009). A autora descreve que tem utilizado essa técnica, em pesquisas nesse cenário, sem a tradicional separação dos participantes por gênero ou categoria profissional.

Esta composição, cuja homogeneidade é garantida pela condição de pertencimento ao PSF, favorecia o objetivo de identificar convergências ou contradiçóes nas opinióes expressas pelos diversos profissionais em relação aos tópicos discutidos. (TRAD, 2009, p. 785),

compreensão semelhante a dos autores desse trabalho.

Nos grupos focais, utilizou-se um roteiro ${ }^{3}$ de perguntas para percorrer os seguintes temas: 1) Principais problemas de saúde do território; 2) Práticas e experiências no cuidado; 3) Relação profissional-usuário; 4) Atendimento Médico; 5) Atendimento de Enfermagem; 6) Trabalho dos agentes e Visitas Domiciliares; 7) Participação na Gestão; 8) Compreensôes sobre acolhimento e humanização/Conhecimento técnico da PNH. Todas as conversaçôes grupais foram gravadas em dois aparelhos de áudio e transcritas na íntegra. Os resultados apresentados neste trabalho são concernentes aos itens $2,3,6,7$ e 8 do roteiro, centrados nos agentes de saúde. Isso se justifica por terem sido esses profissionais que participaram ativamente dos grupos focais em todas as unidades. Os profissionais das outras categorias, além de estarem em menor quantidade pela própria conformação das equipes, tiveram participaçôes com significativas limitaçôes. Os trabalhadores das áreas administrativas (três digitadores e uma recepcionista) se expressaram bem menos, os médicos não participaram e os da enfermagem (nível técnico e superior), em quase todos os serviços, não permaneceram durante todo o grupo focal. Elas saíam da sala e retornavam, pois eram chamadas para resolverem questôes administrativas e assistenciais. $\mathrm{O}$ fato dos grupos focais terem ocorrido nas unidades, mesmo em horários decididos pelos participantes, acarretou limitaçóes importantes. A rede de saúde tinha como prática o fechamento pontual às 16 horas, não sendo possível a permanência nas dependências para a realização das atividades em horário após o expediente; por isso os grupos focais foram realizados nos horários de final de período, quando os atendimentos médicos já haviam se encerrado. Mesmo assim, os profissionais de enfermagem não se desligaram totalmente de suas tarefas. Com isso, o material dos grupos focais se configurou como expressivo das conversações dos agentes comunitários de saúde.

As perguntas que orientaram a análise de conteúdo, de acordo com Minayo (2004) foram: quais são as implicaçóes subjetivas para os trabalhadores, especificamente para os agentes de saúde, ao se esforçarem por trabalhar de modo humanizado? Seja por intuição, por habilidades e competências pessoais, ou por orientação técnica e política. Qual a relação dessas repercussóes com o cuidado em saúde no cotidiano pesquisado? Focalizaram-se as conversaçóes dos agentes concernentes ao acolhimento dos usuários, basicamente em suas visitas e nas unidades, ao escutarem as pessoas, se sensibilizarem, implicando-se em ajudá-las com empenho frente às demandas. O quadro teórico que dá sustentação ao estudo e inspira as análises das comunicações nos grupos focais é a perspectiva da psicologia social filiada ao construcionismo social. Segundo Gergen (2010), a perspectiva construcionista social parte do pressuposto de que os sentidos sobre a realidade são criados através de nossas atividades comunicacionais e colaborativas; de que nossas construçóes de sentido sobre as coisas estão enraizadas em nossas relações sociais, em discursos elaborados em diferentes comunidades ou por diferentes tradiçóes culturais que, por sua vez, referenciam de algum modo nossas crenças, ações e entendimentos sobre "[...] qualquer coisa tradicionalmente aceita como verdadeira, racional ou correta." (GERGEN, 2010, p. 22).

\section{Resultados e discussões}

As agentes de saúde (na maioria mulheres), de modo geral, participaram ativamente das conversaçóes em todos os grupos focais. Havia o entendimento coletivo sobre seu papel profissional e suas atribuiçôes, com o predomínio de posturas de implicação pessoal. Elas reconheciam que a população espera dos agentes a resolução de suas necessidades, mas que, por vezes, fogem à sua alçada, demandando parcerias, trabalho em rede, conforme vemos a seguir:

(Coordenadora do grupo focal): Qual vocês acham que é o papel do agente nestas situaçóes de acolher as pessoas?

ACS $^{4}$ 4: Detectar o problema, informar o paciente, informar a unidade e pra isso precisa de outras parcerias, mas ai que falha... 
(Coordenadora) A gente pode pensar que o acolbimento precisa de parcerias e isso nem sempre acontece?

ACS 3: Falta trabalho em rede... quando precisa de fora, ai...

ACS 5: Quando precisa de um serviço especializado, da Secretaria [Municipal de Saúde] ou mesmo que o paciente tem que ir pra fora [outro município]... ai não funciona... Ai não depende mais de nós...

ACS 1: Os pacientes cobram muito de nós, agentes de saúde, como se fôssemos nós que resolvêssemos... Dai eu explico que não sou eu que marco exames, essas coisas...

\section{(GRUPO FOCAL, unidade básica 2).}

Em outra unidade, os depoimentos também ressaltavam as dificuldades do trabalho em rede e a disposição dos agentes em "correr atrás", entretanto, a "falta de respaldo", de retorno dos profissionais e dos setores parceiros em potencial, mobilizava sensaçôes de solidão, de "falta de apoio", "falta de atenção":

ACS1: Eu acho assim que... As palavras seriam mais estas, às vezes a gente corre atrás das coisas pro paciente e a gente não tem um respaldo pra aquilo que a gente tá procurando.

(Coordenadora do grupo focal): $E$ esse respaldo é o que? Se pudesse nomear este respaldo seria o que? O que vocês colocariam como sugestóes?

ACS1: É complicado.

ACS 2: Eu diria assim: até falta de atenção.

ACS 3: Na minha área mesmo eu tô com um caso assim que essa semana, hoje, semana passada eu fui, hoje eu fui na assistência social. Porque eu quero falar com a assistente social e eu não consigo falar, ou seja, amanhã eu vou de novo e se eu conseguir, bem. Então eu acho assim, ela já poderia... porque eu já deixei meu nome, já falei a unidade que eu trabalho, ela poderia ter pelo menos ligado e falado o que tá acontecendo: “- por que você tá tão atrás de mim?"A gente não tem uma atenção.

\section{(GRUPO FOCAL, unidade básica 7).}

A "falta de atenção" é exemplificada por uma das participantes; a sensação de impotência e as reclamaçốes sobre a falta de respaldo são mais evidentes nas situações cujas problemáticas de saúde são agravadas pelas precárias condiçóes socioeconômicas, em que pessoas vivenciam necessidades de subsistência. $\mathrm{Na}$ visão coerente das informantes ao princípio da integralidade, essas condiçôes afetam diretamente o autocuidado e a saúde dos usuários, por exemplo, as questôes nutricionais de uma pessoa diabética, conforme se segue.

(Coordenadora) E qual a necessidade [da familia, usuário] deste caso que você tá procurando ajudar?

ACS 3: Essa mulher da minha área é uma pessoa nova até, de idade, mas ela é uma pessoa muito sofrida, ela tem diabetes, ela tem hipertensão, ela tem depressão, tá com problema no pulmão e agora ela tá fazendo hemodiálise. E eu quero vê se a assistente social vai lá fazer um auxílio doença, um Vale Renda, alguma coisa pra aquela mulher, porque tem dia que ela não tem um pão pra comer.

\section{(Coordenadora): Ela mora com quem?}

ACS 3: Mora ela e o marido, o marido é alcoólatra chega em casa quebrando tudo, e ela tá assim, tá de cama mesmo. A situação dela não tá legal, e ela tá conseguindo arroz com feijāo porque eu consegui a cesta no CRAS. A menina foi, deu a cesta, todo mês bonitinho ela pega, mas tipo assim... não é arroz e feijão que a pessoa vai vivendo né? Igual... ela tem diabetes, tem que tá comendo... ou as vezes não come. Igual... teve vezes de eu ir vê o diabetes dela e tá 56, tá baixa, ela tinha que tá comendo alguma coisa né? Pra controlar. Então é assim, eu acho que um pouco é a falta de atenção. Pra dá atenção pra gente, porque se eu fui atrás é porque eu tô vendo que a situação não tá legal. Então dá uma atençãozinha [...]. Para, vamo sentar, vamo vê, se é da assistente social ou se você tem que falar é com o Secretário, com o Prefeito ou com quem que seja, sabe? Acho que um pouco é a falta de atenção com os próprios funcionários mesmo, sabe?

\section{(GRUPO FOCAL, unidade básica 7).}

A tentativa da agente em agir de modo intersetorial, visivelmente em prol da cidadania, buscando recursos de assistência social para tentar promover transformaçôes na condição de vulnerabilidade social, está em consonância com as proposiçôes programáticas, como a promoção da cidadania, definidas oficialmente para os agentes de saúde. No entanto, quando a rede intersetorial não está articulada e os recursos de suporte social para a 
proteção dos direitos sociais não estão disponíveis, ou são insuficientes, os agentes vivenciam situaçóes de impotência, prejudicial do ponto de vista do bem-estar e da subjetividade do trabalhador. Dejours (2004) afirma que a subjetividade no trabalho é experimentada na singularidade irredutível de uma encarnação, ou seja, de um corpo particular e de uma corporeidade absolutamente única, apontando para as implicaçôes pessoais do envolvimento com o trabalho.

As possibilidades e os limites das intervenções no trabalho dos agentes comunitários de saúde, com relação às demandas sociais que lhes são apresentadas pela comunidade no cotidiano do processo de trabalho, também é objeto de discussão do estudo de Malfitano e Lopes (2009), realizado na região central da cidade de São Paulo com significativos indicadores de vulnerabilidade social. As autoras utilizam uma expressão emblemática - "atrás da porta que se abre" - para ressaltarem a magnitude das demandas dirigidas aos agentes e de modo geral à Estratégia Saúde da Família "que não se caracterizam como estritamente ligadas à saúde" (MALFITANO; LOPES, 2009, p 365), "demandas estas que podem ou náo estar relacionadas a açóes de saúde básica, mas que são, na maioria das vezes, ações sociais básicas" (MALFITANO; LOPES, 2009, p. 367). Numa discussão mais ampla, sobre o papel do Estado e o potencial das políticas e programas sociais possibilitarem concretamente formas de consolidação das redes sociais de suporte para aqueles em situação de vulnerabilidade social, as autoras concluem que, no território analisado, não se observou, com relação ao trabalho dos agentes,

[...] a efetivação de intervençóes sociais que ultrapassassem os limites de seu núcleo de atuação naquele território. [...] apenas, açōes isoladas e pontuais como resposta para as necessidades da populaçáo, restritas aos seus limites, sem configurar-se de modo a atingir as potencialidades dessas intervenções. (MALFITANO; LOPES, 2009, p. 368).

Entre outras, estaria a "[...] dificuldade de efetivação da intersetorialidade no cotidiano do trabalho [...]" (MALFITANO; LOPES, 2009, p. 370), ressaltada "[...] como elemento potencializador das ações em políticas públicas [...]” (MALFITANO; LOPES, 2009, p. 368), o que também emergiu no presente estudo.

Silva e Dalmaso (2002), por sua vez, num debate a respeito das atribuiçóes dos agentes comunitários de saúde, destacam os desafios existentes no processo de formação destes profissionais em função da existência de uma dimensão em seu trabalho ainda pouco reconhecida, mas que tem se associado às suas atribuiçóes, que seria a dimensão da assistência social. Vê-se que no depoimento acima uma ACS cita a articulaçáo com o CRAS (Centro de Referência de Assistência Social), um dos principais serviços da atual política para esse setor no Brasil.

Alguns agentes de nosso estudo buscavam resolver questōes, como o acesso a recursos (cesta básica, por exemplo) e aos serviços, o que corresponde à racionalidade técnica, mas também se esforçavam para integrar as dimensóes de exclusão e cidadania. Isso pode ser ilustrado pelo trecho a seguir, relativo a outra unidade de saúde, em que também emergiu no grupo focal a dificuldade de construçáo da parceria com a Assistência Social, assim como a morosidade e a burocracia no acesso aos recursos procurados.

ACS 3: Não é agora, nem com essa enfermeira, mas já teve problema não só comigo, mas com os demais colegas... de paciente estar necessitado de uma cesta de alimento e você ter condiçōes de ir direto à Assistência Social pedir e tentar conseguir uma cesta, mas tem que trazer um papel pra chefe poder ligar para ver se eles podem atender, sabe? Sendo que você pode pegar o seu carro, sua moto ou sua bicicleta e já ir direto falar com o secretário da Assistência Social.

(Coordenadora): Dá uma sensaçáo de que se pode fazer mais, caminhar e resolver. Tem alguém que náo concorda com isso, que acha assim: "não, eu prefiro levar mesmo [a demanda] para o enfermeiro, para o médico"?

ACS 6: Se o enfermeiro talvez resolvesse pra nós... mas isso não é resolvido, marca ali e por ali fica, então talvez se... eu concordo.

\section{[...]}

(Coordenadora): O que vocês sentem quando tentam e não conseguem resolver?

\section{ACS 5: Inútil.}

ACS 4: As vezes acha que o morador vai ganhar, ai vai, a assistente social fica de ir na casa e não vai, já aconteceu comigo da assistente social nunca ter ido na casa e não dá nem satisfação, nem liga para falar que não achou o endereço ou coisa assim.

\section{(GRUPO FOCAL, unidade básica 4).}

Silva e Dalmaso (2002) afirmam que os agentes de saúde são envolvidos e se envolvem no desafio 
de juntar o polo técnico, ao polo político das propostas, conforme se evidenciou acima. No entanto, esse engajamento pode ser desgastante, segundo apontam nossos resultados. Um fator adicional nessa circunstância apresenta-se na fala da ACS 3, que argumenta a favor de uma maior permissão institucional à autonomia dos agentes em atuar nas articulaçóes intersetoriais. A tensão remete a um aspecto implícito, relativo à hierarquia e à desigualdade de poder entre agentes de saúde e enfermeiros. Consta-se a insatisfação da participante ao avaliar que encaminhar, somente, as demandas sociais à ciência da enfermeira da equipe não dinamiza, necessariamente, a continuidade do processo de articulação, a partir do que ela identificou como necessidade. É interessante notar que, na percepçáo dessa pessoa, seu empenho não é válido por si só; sem a resolução do problema, o empenho se converte em sentir-se inútil, adjetivo que soava com intensidade no grupo focal e expressava uma sensação consensual entre as agentes participantes.

Jardim (2007) destaca que a falta de compasso entre as demandas da populaçáo e a disponibilidade dos recursos e serviços dificulta as relaçóes de confiança entre a população e os trabalhadores, ocasionando conflitos interpessoais, instabilidade nas relaçôes de trabalho, assim como prejuízos à produção, à qualidade do trabalho e ao atendimento em saúde. Configura-se, assim, a baixa resolutividade do sistema de referência/contrarreferência e do potencial de ação da equipe de saúde.

Uma das agentes participantes relatou o caso de uma senhora cujo filho havia falecido recentemente, e a profissional refletia sobre suas limitaçôes para acolher a usuária mediante respostas que sanassem ou diminuíssem sua dor.

ACS 1: Não dá pra falar... Eu não sei o que a senhora tá passando porque eu não sou mãe. Igual... tem uma paciente, ela perdeu filho muito repentino, de repente ficou doente e morreu. Então não dá pra você falar: "_e eu sei o que o que você tá sentindo". O que aconteceu, no meu caso com ela... eu trato os sintomas que ela adquiriu. Eu sei que ela tem pressão alta, outras coisas que não a questão da morte, talvez conversar. Eu tenho a minha mãe, tenho os meus irmãos todos, o mais próximo que eu já perdi foi um primo, a pessoa sabe que você não conhece aquele sentimento, então não dá nem pra falar diretamente. Então você acaba falando outras coisas, eu sempre vou lá, quando eu vou... Igual, ontem eu vi ela, ela depois foi lá em casa, pediu pra eu medir a pressão pra ela, eu medi.

\section{(Coordenadora): Ela chegou a compartilhar alguma coisa com você?}

ACS 1: Aí ontem ela foi lá em casa, falou... e começou a chorar, falou que ontem foi no cemitério. Lembrei de toda situação, então é uma questão que você sabe, mas não dá pra falar nada.

\section{(Coordenadora): Como é que você lidou com a situação?}

\begin{abstract}
ACS 1: Eu falei assim: “_você tomou os remédios pra pressão? Tomou os remédios que você toma, os controlados?" Ela falou "_ ah eu tomei." Ai eu falei: "_então vai pra casa, tenta descansar, come alguma coisa." É o que eu pude fazer. A gente tenta cuidar do físico da pessoa.

\section{(Coordenadora): E dá pra separar, cuidar do físico e do mental?}

\section{ACS 1: É difícil, bem dificil.}

\section{(GRUPO FOCAL, unidade básica 3).}

Esse tipo de episódio evidencia a necessidade dos agentes por apoio técnico e formação continuada que contribuam para a produção de repertórios comportamentais/práticos, ancorados não somente na sensibilidade e na intuição, mas também em conhecimentos técnicos para lidar com esse tipo de demanda. No caso, a demanda que interpela a agente a ter uma postura de escuta e apoio, princípios da humanização da assistência, exige alguns conhecimentos e habilidades de manejo concernentes à assistência primária em Saúde Mental, tema a ser mais fortemente contemplado na educação permanente dos trabalhadores - além de ser uma área programática a ser acompanhada pela gestão. Embora de extremo valor: a disponibilidade da profissional em conversar e em "cuidar do físico" da senhora, ressalta-se o quanto a agente se viu sem recursos para lidar com uma situação envolvendo a vivência de um luto da paciente hipertensa.

Em outra unidade, o depoimento de uma das agentes comunitárias sobre o caso de um jovem, ao que indica, em situação de sofrimento psíquico, é bastante expressivo de seu engajamento no trabalho, emergindo, novamente, o tema da Saúde Mental. Ela disse: "[...] um rapaz na minha área que é o que mais me choca, ele era uma pessoa assim normal... Entrou em depressão [...]". A agente crê "fazer a sua parte", mas reconhece que isso é insuficiente. 
(Coordenadora do grupo focal): Este jovem, por exemplo, tem alguma coisa que o posto tem feito por ele, quais sáo as açóes que o posto tem a possibilidade de fazer?

ACS 1: Bom a minha parte eu faço né, minha parte eu faço pra ele, a minha parte sempre que dá eu faço, a mãe dele não pode sair porque tem que ficar com ele, eu levo remédio pra ela, remédio pra ele.

\section{(Coordenadora): Ela também toma medicação?}

ACS 1: Eu passei pra minha enfermeira, ai como se diz: "_até onde en pude fazer eu fiz."

\section{(GRUPO FOCAL, unidade básica 7).}

Conforme aponta Teixeira (2003) sobre a noção de acolhimento-diálogo, pode-se dizer que os dois trechos acima evidenciam o quanto o trabalho dos agentes de saúde se alicerça na dimensão comunicacional e conversacional, que caracteriza as posturas de acolhimento, ponto de partida para a produção processual das açóes assistenciais.

O acolhimento-diálogo corresponde a uma espécie de protocolo geral de comunicação entre todos os elementos que compóem a rede. Assim, não se trata necessariamente de uma atividade em particular, mas de um conteúdo de qualquer atividade assistencial. É dessa forma, entáo, que o acolhimento-diálogo desempenha papel fundamental na dinâmica organizacional, redundando em encaminhamentos, deslocamentos, trânsitos pela rede assistencial, que são, em última instância, o resultado do que se passa e das decisóes tomadas num encontro pautado pelas já mencionadas disposiçóes "morais" e "cognitivas". Trata-se rigorosamente de uma técnica de conversa, um diálogo orientado pela busca de uma maior "ciência" das necessidades de que o usuário se faz portador, e das possibilidades e dos modos de satisfazê-las. (TEIXEIRA, 2003).

No caso específico dos agentes, espera-se que esses acolhimentos-diálogos repercutam em continuidade de açóes pelo agente e/ou por algum profissional da equipe, como a enfermeira no caso acima, da qual a agente espera alguma ação de cuidado dirigida à pessoa com depressáo. Em outro grupo, ao se explorar situaçóes expressivas da necessidade do agente dialogar com os usuários, essa prática é valorizada, mas de alguma forma é vista como associada ao trabalho de outra categoria profissional, que não a de agente comunitário de saúde.

\section{Coordenadora: Contem algum caso, entáo, que teve necessidade de diálogo.}

ACS4: Tem uma paciente minha que ela veio pra cá faz pouco tempo. A mãe mora aqui, os irmãos. Ai tinha uma filha que também veio com a netinha. E agora no periodo das férias eu passei em frente à casa dela e tava tudo fechado. Ai a vizinha falou que só tava ela, que a filha e a netinha tinha ido embora. Fui lá conversando com ela, ela tava bem deprimida, a ausência da neta, principalmente, porque a filha não quer conversar com a mãe. As duas foram embora. [Eu disse:] "_pra saber notícias da neta, a senhora tem que ligar". Ela diz que tá sentindo muita falta de netinha, faz falta, principalmente a noite na hora da janta, ela mora sozinha, também tem o problema dela náo ter serviço, ela tem uns 46 anos e tá desempregada. Ela vai acabar deixando a máe dela e voltando pra lá por causa da neta.

(Coordenadora): Vocês, agentes, se sentem seguros, preparados, quando há expectativas em relaçáo a vocês que náo é pra arrumar consulta? É pra conversar... Como se sentem? Alguma dificuldade?

ACS2: A nossa área é de bastante idoso e que mora sozinho, muitos não têm nem necessidade de visitas do ACS, eles querem mesmo é ter alguém pra conversar, a gente fica mais escutando, faz trabalho de psicólogo, tem muitas coisas que você nem tem como dar um palpite, conselho nada, tem só que escutar o problema dela

\section{(GRUPO FOCAL, unidade básica 3).}

Os acolbimentos-diálogos tendem a se produzir a todo o momento enquanto os agentes circulam no território, inclusive fora dos horários de expediente e em situaçôes complexas que demandam escutas, manejos, identificação de demandas e concretização de açôes por parte dos agentes. O trecho a seguir, em que uma agente expôs o caso de uma família em que todos estavam doentes é muito ilustrativo de seu engajamento e das implicaçóes intersubjetivas.

ACS 1: Quatro doentes na mesma casa: pai, mãe, filho e filha. E uma filha que tá internada no hospital psiquiatrico, uma das melhores ideias dela era se matar. Um dia ela tirou um pedaço de vidro da tampa da geladeira la agente comunitária foi chamada pelos familiares da jovem] e eu consegui... saí de lá 10 horas da noite. [A filha] tinha espetado a [própria] barriga. Então é assim: o ACS é chamado a qualquer hora do dia, da noite, feriado, no final de semana, é o socorro da população, tá? Então, a gente chega 
[na unidade] e fala pra enfermeira [nome da profissional]: "_ a gente tem que conversar" E ela fala: "_Ih [nome da agente] até sei".

\section{(Coordenadora do grupo focal): $O$ que vocês fazem pra cuidar da própria saúde?}

Técnica enfermagem: $A$ maioria dos funcionários da saúde toma remédio pra ansiedade.

Recepcionista: Antes, há uns dois, três meses atrás, acontecia de eu ficar muito ruim. Assim, o paciente tá precisando ser atendido e não tem como, não tem como encaixar, e aquilo não me deixa bem e eu ficava assim é... ruim mesmo. E eu ia pra casa e aquilo ficava na minha cabeça, ai no outro dia quando o paciente passava pela consulta que eu melhorava. Eu pensava assim: " gente e se for alguma coisa de precisão mesmo né?” Ai você pegava e ficava com um peso na consciência né?

\section{(GRUPO FOCAL, unidade básica 1).}

O trecho acima corrobora os apontamentos do trabalho de Jardim (2007) acerca dos agentes de saúde manterem contatos constantes com a populaçáo, principalmente fora do horário do trabalho, se expondo ainda mais aos riscos à saúde e à perda do bem-estar no (e pelo) trabalho. A produção do sofrimento das agentes de saúde, mas não somente por essa categoria (como indicam as falas acima, da técnica de enfermagem e da recepcionista), se dá nas circunstâncias em que elas se deparam com situaçôes complexas, com seus próprios limites sobre como proceder, ou com as limitaçóes estruturais, como, por exemplo, o limite de vagas para passar em consulta médica, apontado pela recepcionista.

Nesse sentido, as implicaçôes subjetivas do trabalho, na medida em que os profissionais são sensíveis às necessidades dos pacientes, não se restringem ao cargo de agente comunitário e à natureza de seu trabalho - mais próximo dos "dramas" cotidianos por circularem no território e morarem no bairro que trabalham. Evidenciam-se, também, nos depoimentos da recepcionista e da técnica de enfermagem; preocupante é o destaque que a participante deu ao uso de ansiolíticos entre os profissionais da saúde.

A angústia e o mal-estar vivenciados pela profissional da recepção associam-se, por sua vez, ao modelo de atendimento da rede básica local, no qual não havia o acolhimento a todos os usuários por enfermeiros, auxiliares ou médicos com a devida avaliação de risco e priorização dos casos a serem atendidos em consulta médica, conforme é preconizado. Ainda se praticava o modelo médicocentrado de distribuição de uma quantidade pré-determinada de vagas, conforme ordem de chegada, sendo de responsabilidade da recepção "frear" a demanda em excesso, dos usuários que solicitavam o "encaixe". Enseja-se, assim, a experiência intersubjetiva entre duas pessoas, a solicitante e aquela que não pode atendê-la, embora se sensibilize com sua necessidade, sentindo-se em parte responsável, conforme se espera de um acolhimento.

A dimensão subjetiva do trabalho e suas implicaçóes para a saúde mental dos trabalhadores em geral são objeto de ampla discussão, já desenvolvida por autores clássicos na área da psicodinâmica do trabalho, entre eles, o expoente Dejours, já mencionado. $\mathrm{O}$ autor ressalta que na vivência do trabalhador, a inadaptaçáo ou o descompasso entre as aptidóes profissionais, as necessidades psicológicas do trabalhador e o conteúdo da tarefa reverberam em insatisfação ou sofrimento, ou até mesmo em estados de ansiedade, raramente traduzidos em palavras e/ou explicitados pelo próprio trabalhador (DEJOURS, 1992).

Durante um dos grupos focais, houve um momento em que os profissionais discutiram a respeito do que acreditavam ser prejudicial aos trabalhadores, gerando cansaço ou estresse. Foi unânime o destaque à "cobrança dos usuários" como prejudicial ao seu bem-estar.

ACS1: Cobrança... é por parte dos usuários, relativo às vagas [de consultas] muita cobrança, cobrança, cobrança, deixa você meio assim desmotivada.

ACS2: [...] É a cobrança devido a nós, fica aqui no Bolsa Família, nós ficamos na vacina, agora a gente tá na pré-consulta. Então a gente deixa a desejar um pouco nas nossas visitas, nós não consegue mais entregar 150. [Entregamos] 100, 120, 130, 140. Então ai eles [os usuários] vem aqui e fala: “_ah o fulano não tá passando". Mas às vezes tem 1 mês, 60 dias não é [...]? [...] ai fica aquela cobrança assim, às vezes, assim, a gente se sente acuado, entendeu?

\section{(GRUPO FOCAL, unidade básica 6).}

Lunardelo (2004) afirma que o agente vivencia ambiguidades de interação, sentimentos e emoçóes no constante contato com a população. A entrada em seus domicílios e, assim, em sua vida privada e em sua intimidade; o envolvimento com a população; o vínculo estabelecido; o conhecimento e a apropriaçáo das demandas dos usuários e as impossibilidades de ação, quando o agente constata os limites do 
setor de saúde, geram sentimentos ambíguos, de prazer e sofrimento. É o que indicam, também, os resultados do presente estudo, no trecho anterior e, também, a seguir:

ACS 2: Nossa! Dá um nervoso. A gente se sente que pode acontecer com a gente, com alguém nosso, e a gente não pode fazer nada. A gente tenta fazer pro próximo e não consegue. Então quem é nós pra nós? Porque a gente pode ter uma pessoa daquele jeito, e aí?

ACS 1: Sem contar que a gente acaba falando com o paciente: "_ ah eu vou vê o que eu posso fazer". E ai o que acontece? E ai depois, talvez ele pensa: “_ah, ela não fez nada, ninguém... não veio vê, ninguém ajudou e acaba com seu trabalho, [a gente] se sente desmerecida. Aconteceu comigo.

\section{(GRUPO FOCAL, unidade básica 7).}

$\mathrm{O}$ ato de trabalhar, seja intelectual ou físico, passa por vezes, pela experiência afetiva do sofrimento por parte dos trabalhadores, seja nos variados sentidos que esse adquire: sentir-se "chocada", "nervosa", "acuada", "cobrada", "desmerecida" ou "desmotivada”, conforme os depoimentos. Não existe sofrimento sem um corpo para experimentá-lo (DEJOURS, 2004), entretanto, o fato do sofrimento ser concretizado no corpo de alguém, que pode vir até mesmo a fazer uso de recurso medicamentoso para dirimi-lo, náo pode secundarizar o contexto que amplia a vulnerabilidade dos profissionais a esse sofrimento, portanto, sua determinação também situacional e coletiva.

Nessa direção, Codo (2004) afirma que é preciso haver o reconhecimento de que a "loucura" do profissional não é tấo sua como parece, ou somente sua. É, por conseguinte, forjada nas suas condiçôes objetivas de vida e de trabalho de seu grupo. $\mathrm{O}$ autor defende que os trabalhadores reivindiquem um ambiente de trabalho psicologicamente sadio, o que ajudaria a reduzir sua impotência perante o estresse e a tensão no trabalho.

Os sentimentos ambíguos produzidos (LUNARDELO, 2004), como também a sensação do agente comunitário ficar desacreditado diante da população (JARDIM, 2007), devem ser reconhecidos e considerados no planejamento e na gestão do trabalho na Atenção Básica em Saúde, ao se incentivar ou exigir que os trabalhadores hajam de modo humanizado com a população.

No entanto, podemos afirmar que espaços coletivos de diálogos, organização e/ou reivindicação não estavam dados na cidade pesquisada, como iniciativas de cogestão. Inclusive, observamos reclamaçóes generalizadas sobre esse aspecto, sobre a falta de espaço por parte dos gestores em escutar e dar respostas programáticas às demandas das equipes de saúde da rede básica, especialmente dos agentes de saúde. Eles destacavam que, entre os agentes e o Secretário Municipal, havia os médicos, as enfermeiras, assim como todos os outros cargos, indicando a percepção de que estavam no nível mais inferior da hierarquia institucional.

$\mathrm{O}$ trecho, a seguir, em que as agentes comentavam casos ilustrativos em que elas haviam se engajado para buscar os recursos que os usuários necessitavam como tomografia, vaga para cirurgia, alimento e, até mesmo, a reativação da energia elétrica suspensa na residência, é ilustrativo da concordância do grupo de que são pouco escutados pela gestão.

\begin{abstract}
ACS 2: [...] eu não sei se o nosso trabalho não tem tanto valor ou assim... A gente não tem como falar com ele [Secretário Municipal], por exemplo, a gente tenta falar com o Secretário, com assistente social e a gente não consegue chegar lá. $N a$ verdade, eu acho assim, o nosso trabalho é muito importante, a gente conhece a cada um, a cada casa, a cada esquina a gente conhece, até que horas chega em casa a gente sabe, que hora que tá, que hora que não tá. Então, assim eu acho que não há nada melhor do que a gente tentar fazer alguma coisa. Eu náo sei o que acontece, sei lá... os órgãos maiores, em fazer uma reuniäo, perguntar, sabe, eu náo sei o que acontece.
\end{abstract}

ACS1: É isso aí mesmo né, fala a mesma língua, a gente tá vendo a realidade.

\section{(GRUPO FOCAL, unidade básica 7).}

Sobre isso, podemos dizer que as proposiçóes da $\mathrm{PNH}$ no que se refere à cogestáo e à maior participação dos trabalhadores nos níveis de planejamento e avaliação, eram incipientes na localidade em questão. Lembrando que a $\mathrm{PNH}$ institui que os processos de trabalho e de gestão são, também, alvos das açôes humanizadoras, devendo se ampliar os espaços de escuta aos trabalhadores, enquanto uma modalidade de acolhimento. Incentiva-se a comunicaçáo entre os trabalhadores e a busca por soluçôes que transformem a cultura institucional da atençáo à saúde para usuários e para trabalhadores do SUS (RIOS, 2008).

Embora se destaquem no conjunto dos seis grupos focais realizados, as manifestaçôes de impotência e frustração, em um dos grupos focais relativo a uma das unidades básicas pesquisada, essas manifestaçôes não tiveram conotaçôes tão 
intensas, quando comparadas ao conjunto dos serviços. Ademais, quando se fizeram presentes estavam mais associadas às queixas com relação a problemas como falta de recursos humanos, principalmente de médicos, e dificuldade de acesso às especialidades. As angústias não pareceram tão associadas à dimensão intersubjetiva: relacional e afetiva, dos agentes com os usuários; à disposição em escutá-los, às preocupaçôes em atendê-los em necessidades que extrapolassem suas possibilidades como agentes e as do setor da Saúde. Nas conversaçóes dos agentes desse grupo focal, identificou-se o predomínio de concepçóes que expressavam boa capacidade de escuta e sentidos de orgulho quanto ao papel de cuidador que desempenham e quanto à segurança e à confiança que inspiram nos usuários. Como nos outros grupos, havia sentidos expressivos de envolvimento com o trabalho, mas se destacaram as expressóes de realização pessoal e profissional, em parte associada à valorização do ACS por parte da população.

ACS2: A nossa população... muitas vezes eles vão no médico, fala com ele, e só inicia o tratamento depois de falar com a gente, eles näo inicia antes, eu tenho vários assim que vão no médico precisa do tratamento mais enquanto eu não for...

\section{$[\ldots]$}

ACS2: Tinha uma paciente que ela teve doença na veia do coração e o médico pediu pra ela fazer o cateterismo, era em Campo Grande né? E tava tudo marcado pra ela fazer e eu tava de férias. Então ela ligava pra mim e tava... desligo, porque eu tava pra fazenda. Nos dias dela ir eu cheguei e ela falou: "_eu tava quase desistindo de fazer o cateterismo porque você não atendia o telefone." Ai eu falei: "_se o médico falou, ele entende tudo e eu não entendo nada de coração." Ai ela falou: “_ eu não sei lê e eu não to entendendo isso. Daí, assim, eu achei muito engraçado ela falar que ia deixar de fazer se eu não aparecesse".

\section{(GRUPO FOCAL, unidade básica 3).}

Nessa direção, o grupo focal desses trabalhadores em que se destacou o polo da positividade, da satisfação com o trabalho, mesmo com o reconhecimento das significativas limitações, vai ao encontro do que destaca Segnini (2010). Com base na psicodinâmica do trabalho, ele afirma que as relaçóes estabelecidas entre o indivíduo e o trabalho são essenciais para a saúde mental do trabalhador, embora tendam a ser permeadas por conflitos e sofrimentos, inscrevendo o trabalho em um continuum entre dois polos de probabilidade: de um lado, o sofrimento patogênico, descompensaçôes psíquicas e crises identitárias, de outro, a criação e o prazer.

Num determinado momento desse grupo focal em específico, os participantes explicaram sobre um modo diferente de relacionamento que vinham construindo com a população, incluindo a equipe como um todo, mais baseado nos diálogos, na cordialidade e nos esclarecimentos sobre as limitaçóes, como, por exemplo, na ausência do médico ou sobre a impossibilidade de passar em consulta ao chegar tarde ao serviço (após a distribuição das vagas). Afirmavam que a população no geral estava menos hostil, mais compreensiva e as interaçôes estavam menos tensas, a partir dessas iniciativas mais comunicacionais $\mathrm{da}$ equipe.

Em seguida, foram exploradas nesse grupo suas ideias em torno das noçóes de acolhimento e humanização. É importante esclarecer, aqui, que, segundo a sequência dos assuntos sistematizados no roteiro, se buscou primeiramente explorar a dimensão do fazer, ou seja, solicitava-se que falassem sobre as experiências cotidianas do trabalho, antes de qualquer exploração das questóes em termos de associação de ideias ou de compreensôes conceituais e técnicas. Por esse aspecto metodológico, em todos os grupos, a solicitação para que discorressem sobre o que era "fazer acolhimentos" ou o que "significavam os termos acolhimento e humanizaçáo" se deu ao final dos grupos focais. Os trechos que se seguem relativos a um desses, ilustram as conceituaçóes que se fizeram presentes de modo semelhante no conjunto dos serviços.

Enfermeira: [acolhimento é] escutar a pessoa, tratar ela com respeito, com educação.

ACS2: Tratar de igual pra igual.

ACS3: Informação né? Dar informação pra pessoa, mesmo que ela náo tenha atendimento, dar informaçôes pra pessoa do que ela tem que fazer né?

ACS4: Tem algumas situaçôes que às vezes uma palavra, talvez... não é tanto problema, assim, de medicamento, talvez um diálogo, conversar.

Finalizando, os depoimentos predominantes dos agentes de saúde apontaram a construção de movimentos pessoais e, também, coletivos (a conformação de pensamentos e de afetos compartilhados entre a categoria profissional) que oscilavam na dialética entre o envolvimento 
e empenho no trabalho à paralisia, frustração e impotência. Isso se mostrou menos marcante em somente um dos serviços, conforme mencionado acima. As expressōes de contrariedades e inquietaçóes vivenciadas pelos agentes, geralmente, associavam-se ao sentido de não conseguirem proporcionar cuidados plenos aos usuários, em especial quando esses demandavam técnicas, procedimentos e coordenação de açôes nos níveis de gestâo da Saúde e das políticas intersetoriais. Ou seja, em situaçóes em que a resolutividade das questôes não dependia somente de açôes dos agentes, embora pudesse se iniciar a partir dessas. Os acolhimentos nas situaçóes de cuidados primários em saúde mental também tinham importantes implicaçóes intersubjetivas.

\section{Considerações finais}

As situaçóes de impotência que os agentes da cidade pesquisada vivenciavam pareciam se produzir em meio à pouca efetivação do tão defendido trabalho em rede, com vias à integralidade. Associavam-se, também, às deficiências de articulação e de comunicação dentro da própria equipe/serviço, às necessidades de qualificação profissional e de apoio aos agentes e às equipes de saúde da família, à falta de repertório pessoal e técnico para lidar com demandas complexas como as que envolvem a área da Saúde Mental, além da ausência de processos de cogestão que fossem sensíveis à dimensão intersubjetiva do trabalho em saúde.

No plano da formação e do desenvolvimento profissional, é preciso investir em estratégias que ajudem os trabalhadores no manejo de tecnologias leves, como aponta Merhy em seus diversos trabalhos. As tecnologias leves, tais como o diálogo, a escuta, o vínculo, a implicação, de acordo com Merhy (1998), são operadas em ato, nos encontros/momentos dialógicos em que profissional e usuário interatuam. É crucial, também, que sejam amparados pelo provimento de uma estrutura com padrão de qualidade condizente com a oferta do cuidado humanizado, produzido pela articulação das tecnologias leves com as duras (insumos, recursos, procedimentos, etc.).

A análise do material nos possibilita formular a seguinte tese: os agentes comunitários de saúde que se empenham nos acolhimentos e em prestar os cuidados de modo humanizado, ao encontrar barreiras de acesso a determinados procedimentos, a um tipo de assistência não disponível, ou ao não se verem respaldados pelo trabalho de sua equipe, podem se sentir impotentes, frustrados ou "inúteis", como destacaram os participantes. Em determinadas circunstâncias se percebiam despreparados para discriminar, exatamente, quais seriam as necessidades em questão, em especial nas situações mais complexas de adoecimento e de vulnerabilidade social.

Mesmo que os significados associados às noçôes de humanização e acolhimento, por boa parte dos participantes, tivessem aproximaçóes com os referencias técnicos do Ministério da Saúde, em especial no plano ético, os resultados evidenciaram um baixo grau de conhecimento dos informantes acerca dessas noçóes enquanto princípios técnicos, éticos e operacionais de uma política específica, a PNH. Essa era totalmente desconhecida, referida como inexistente, não implantada, no nível municipal. Entre outras implicaçôes dessa "não implantação" e do desconhecimento da $\mathrm{PNH}$, o acolhimento não era reconhecido pelas equipes dos serviços como um dispositivo que deveria transformar a lógica dos atendimentos médicos por ordem de chegada e distribuição de vagas.

$\mathrm{O}$ acolhimento e a humanização eram significados mais como "filosofias" sobre como deveria ser uma "boa relação profissional-paciente". Nessa ótica, os dados apresentados apontam para uma questáo central a ser considerada ao se conceber a $\mathrm{PNH}$ como uma política transversal no SUS. Ao se incentivar (ou exigir, no caso de gestóes verticais) que "os agentes sejam humanos e acolhedores" e que trabalhem com base na integralidade, emerge a seguinte implicação: a qualidade geral do sistema $e$ do desenvolvimento da política de saúde local, em que se desenvolve o trabalho do agente comunitário, afeta suas possibilidades reais de produção do cuidado humanizado, a sustentabilidade de seu engajamento em trabalhar em prol do acolhimento, assim como afeta as dinâmicas subjetivas e intersubjetivas envolvendo profissionais e população.

De modo mais amplo, estamos falando de uma maior ou menor permeabilidade da Atenção Básica em Saúde pela Política Nacional de Humanizaçáo, que estará condicionada à qualidade geral do SUS, da rede básica e do perfil de gestão local.

As implicaçóes da má qualidade programática, assim como da precariedade do trabalho em rede e do trabalho interdisciplinar em equipe na cidade pesquisada, repercutem sobre a subjetividade no trabalho, sobre a saúde e a dimensão psicossocial dos agentes. Além, claro, de afetarem negativamente a resolutividade e a integralidade do cuidado. Portanto, o cenário programático e suas repercussóes objetivas e intersubjetivas no trabalho do agente de saúde podem configurar obstáculos ou facilitadores à concretização da $\mathrm{PNH}$; no caso da localidade estudada, são obstáculos, tanto na perspectiva da 
qualidade assistencial quanto da gestão do trabalho em saúde.

Do ponto de vista da humanização da gestáo, necessita-se de uma participação mais efetiva dos gestores locais na reorganização dos processos de trabalho, para que se desloque o eixo central do médico para uma equipe multiprofissional, valorizando as outras categorias profissionais por meio de melhores condiçôes de trabalho, da escuta e da valorização de suas percepçóes e reflexōes sobre o trabalho cotidiano.

Além de um dispositivo que oportuniza envolvimento, vínculo e empatia na interação trabalhador-usuário, o acolhimento tem sido descrito, também, como um analisador dos modos de se operar não só a assistência, mas também a gestão; como dispositivo que dispara algo que nos força a pensar em maneiras de fazer inovadoras (BRASIL, 2006b). Sugere-se, fortemente, a necessidade de rever a organização do processo de trabalho e de gestáo de unidades de saúde cujo panorama se caracterize pelo predomínio de limitaçôes de ordem técnica e estrutural, tomando como referência os princípios da PNH, assim como também a necessidade de reconhecer e considerar as peculiaridades da atuação dos agentes de saúde e sua necessidade de apoio contínuo.

Para efetivar serviços de saúde de acordo com as noções de humanização e acolhimento (BRASIL, 2006b), nos quais todas as pessoas sejam atendidas em suas demandas, partindo de conversaçóes que garantam o acesso universal, exige-se o compromisso de toda a equipe em acolher e escutar, assim como a sustentabilidade do trabalho iniciado pelo agente, por vezes, condicionada à busca de recursos dos níveis: secundário e terciário, e também, intersetoriais.

Campos (2003, p. 129) afirma que os “[...] processos subjetivos [como a interaçáo e a comunicação] nunca poderão ser dissociados dos processos políticos e técnicos." Nessa dissociação, há uma grande parte da alienaçáo no trabalho, com a recusa à subjetividade. A autora afirma que o grau de 'objetualização' ocorrido no processo de trabalho em saúde deve ser reduzido ao mínimo, aumentando a possibilidade de encontros humanizados.

Os resultados evidenciam narrativas de empenho, de boa parte dos agentes, em atuar com acolhimento e humanização e, dialeticamente, a produção de sentimentos e de emoçóes não somente benéficas, mas também e, principalmente, adversas tais como: frustraçáo, impotência e sentimentos de inutilidade, em meio aos obstáculos estruturais do SUS e à insipiência das conversaçóes necessárias ao trabalho em equipe, intersetorial e em rede.

Pela presença menor das outras categorias profissionais nos grupos focais, assim como pelas diferenças inerentes às funções, não é possível fazer consideraçôes mais aprofundadas a respeito de suas colocaçôes, ou seja, há uma limitação do estudo que culminou com a pertinência de produzir um trabalho sobre os agentes de saúde e não sobre os trabalhadores da Estratégia Saúde da Família como um todo. Pode-se, no entanto, dizer que as expressóes faciais e algumas complementaçôes das conversaçôes indicavam concordância da parte dos participantes de outras categorias profissionais, com os fatos relatados e, principalmente, solidariedade aos colegas agentes; alguns faziam comentários reconhecendo o quão "duro" era o trabalho dos ACSs. De modo geral, o trabalho na saúde era visto como árduo pelas diferentes categorias profissionais.

Pela especificidade do ACS, dentre os trabalhadores de saúde, em residir e trabalhar no mesmo território, desenvolvendo uma relaçáo de pertença (BACHILLI; SCAVASSA; SPIRI, 2008; JARDIM, LANCMAN, 2009), deve ser intensificada a sensibilidade dos gestores para os riscos à saúde mental dos trabalhadores em geral, mas em especial dos agentes de saúde, assim como as estratégias para sua promoção e proteção.

Para isso, é relevante recuperar compreensóes mais humanizadas sobre o trabalho, como as de Dejours que argumenta que todo trabalho vem a ser

[...] gestos, saber-fazer, um engajamento do corpo, a mobilização da inteligência, a capacidade de refletir, de interpretar e de reagir às situaçóes; é o poder de sentir, de pensar e de inventar, etc. (DEJOURS, 2004, p. 28).

O trabalho não é, em primeira instância, a relação salarial; é o "trabalhar", ou seja, o engajamento da personalidade a fim de responder a uma tarefa delimitada por pressóes. À experiência do sujeito em resistir às pressóes do mundo social, associa-se o desenvolvimento da inteligência e da subjetividade, aspectos positivos e produtores de bem-estar no trabalho.

O sofrimento que se produz no trabalho, resultado do encontro com o real, ao mesmo tempo marca uma ruptura de determinada ação ou de determinado modo de sentir e de agir no trabalho. Segundo o autor,

[...] ele [o sofrimento] não é apenas o resultado ou o fim de um processo que une a subjetividade ao trabalho. O sofrimento é, também, um ponto de partida. (DEJOURS, 2004, p. 28). 
Inspirados por essa afirmação, os gestores que almejam concretizar os princípios da PNH e do SUS devem, como ponto de partida, ofertar espaços aos agentes e às equipes de saúde da família, a fim de reconhecer e acolher as percepçóes, manifestaçóes emocionais e concepçóes dos trabalhadores. Devem compreender sua produçáo coletiva, não as tomando somente como problemas de ordem pessoal de um ou outro trabalhador. Os trabalhadores devem ser apoiados no desenvolvimento de repertórios comportamentais, pessoais e profissionais, para lidar com as agruras do trabalho em saúde. Nesses espaços e em quaisquer canais de diálogos, os sentimentos de impotência e frustração devem ser expressos, ressignificados e, principalmente, considerados pelos gestores como expressivos de problemas e falhas estruturais ou processuais a serem aprimoradas e de desafios a serem superados.

Nessa direção, os gestores da saúde devem ter como parte de suas atribuiçôes a comunicação sistemática com gestores das outras Secretarias ligadas às políticas sociais para a pactuação de estratégias que efetivem ações, abordagens e programas intersetoriais, com vias à humanizaçáo do cuidado, qualidade de vida, promoção da saúde e da cidadania.

\section{Referências}

BACHILLI, R. G.; SCAVASSA, A. J.; SPIRI, W. C. A identidade do agente comunitário de saúde: uma abordagem fenomenológica. Ciência e Saúde Coletiva, Rio de Janeiro, v. 13, n. 1, p. 51-60, 2008. http://dx.doi. org/10.1590/S1413-81232008000100010

BRASIL. Ministério da Saúde. Secretaria de Atenção à Saúde. Departamento de Atençáo Básica. Politica nacional de atenção básica. Brasília: Ministério da Saúde, 2006a. (Série A. Normas e Manuais Técnicos; Série Pactos pela Saúde 2006, v. 4). ISBN 85-334-1186-3.

BRASIL. Ministério da Saúde. Secretaria de Atenção à Saúde. Núcleo Técnico da Política Nacional de Humanização. Acolhimento nas práticas de produção de saúde. Brasília: Ministério da Saúde; 2006b. (Textos Básicos de Saúde).

BRASIL. Ministério da Saúde. Política Nacional de Humanização (PNH). Cartilha da PNH: Acolhimento com classificação de risco. Brasília: Ministério da Saúde; 2004. 43 p. ilus. (B. Textos Básicos de Saúde).

CAMPOS, R. O. Reflexôes sobre o conceito de humanização em saúde. Saúde em Debate, Rio de Janeiro, v. 27, n. 64, p. 123-130, mai./ago. 2003.

CAMPOS, G. W. S. Um método para análise e co-gestão de coletivos. São Paulo: Hucitec, 2000.

CODO, W. O que é alienação. São Paulo: Brasiliense, 2004. (Coleção Primeiros Passos).
DEJOURS, C. Subjetividade, trabalho e ação. Produção, São Paulo, v. 14, n. 3, p. 27-34, set./dez. 2004. http:// dx.doi.org/10.1590/S0103-65132004000300004

DEJOURS, C. A loucura do trabalho: o estudo de psicopatologia do trabalho. 5. ed. São Paulo: Cortes, 1992.

FERREIRA, A. B. H. Novo Dicionário Aurélio. Rio de Janeiro: Nova Fronteira, 1975.

FORTES, P. A. C. Ética, direitos dos usuários e políticas de humanização da atenção à saúde. Saúde e Sociedade, São Paulo, v. 13, n. 3, p. 33-34, set./dez. 2004.

FRANCO, T. B.; BUENO, W. S.; MERHY, E. E. O acolhimento e os processos de trabalho em saúde: o caso Betim-MG. Cadernos de Saúde Pública, Rio de Janeiro, v. 15, n. 2, p. 347, abr./jun. 1999.

GERGEN, K. Construcionismo Social: um convite ao diálogo. Rio de Janeiro: Instituto Noos, 2010.

GONDIM, S. M. G. Grupos focais como técnica de investigaçáo qualitativa: desafios metodológicos. Paidéia (Ribeirão Preto), Ribeirão Preto, v. 12, n. 24, p. 149-161, 2002. Disponível em: <http://www.scielo.br/scielo. php?script=sci_arttext\&pid=S0103-863X20020003000 04\&lng=pt\&nrm=iso>. Acesso em: 10 jul. 2012. http:// dx.doi.org/10.1590/S0103-863X2002000300004

JARDIM, T. A.; LANCMAN, S. Aspectos subjetivos do morar e trabalhar na mesma comunidade: a realidade vivenciada pelo agente comunitário de saúde. Interface: Comunicacao, Saude, Educacao, Botucatu, v. 13, n. 28 , mar. 2009. Disponível em: <http://www. scielo.br/scielo.php?script=sci_arttext\&pid $=$ S1414$32832009000100011 \& \operatorname{lng}=\mathrm{pt} \& \mathrm{nrm}=\mathrm{i}$ so $>$. Acesso em: 05 ago. 2011. http://dx.doi.org/10.1590/ S1414-32832009000100010

JARDIM, T. A. Morar e Trabalhar na Comunidade: a realidade dos agentes comunitários de saúde. 2007. 120 f. Dissertação (Mestrado em Ciencias da Reabilitação)Faculdade de Medicina, Universidade de São Paulo, São Paulo, 2007.

LIMA, J. C.; MOURA, M. C. Trabalho atípico e capital social: os agentes comunitários de saúde na Paraíba. Sociedade e Estado, Brasília, v. 20, n. 1, p. 103-133, jun./ abr. 2005.

LUNARDELO, S. R. O trabalho do agente comunitário de saúde nos Núcleos de Saúde da Família em Ribeirão Preto - São Paulo. 2004. 154 f. Dissertação (Mestrado em Enfermagem)-Escola de Enfermagem de Ribeirão Preto, Universidade de São Paulo, Ribeirão Preto, 2004.

MALFITANO, A. P. S.; LOPES, R. E. Educação popular, ações em saúde, Demandas e intervençóes sociais: $\mathrm{O}$ papel dos agentes comunitários de saúde. Cadernos Cedes, Campinas, v. 29, n. 79, p. 361-372, set./dez. 2009. http:// dx.doi.org/10.1590/S0101-32622009000300006

MERHY, E. E. A perda da dimensão cuidadora na produção da saúde - uma discussão do modelo assistencial e da intervençáo no seu modo de trabalhar a assistência. In: CAMPOS, C. R. et al. Sistema Único de Saúde em Belo Horizonte: Reescrevendo o público. São Paulo: Xamã, 1998. p. 103-120. 
MINAYO, M. C. S. O desafio do conhecimento: pesquisa qualitativa em saúde. 8. ed. São Paulo: Hucitec, 2004.

PUPIM, V. M. Agentes Comunitários de Saúde: concepções de saúde e do seu trabalho. 2008. 169 f. Dissertação (Mestrado em Psicologia)-Faculdade de Filosofia, Ciência e Letras de Ribeirão Preto, Universidade de São Paulo, Ribeirão Preto, 2008.

RIOS, I. C. Humanização e ambiente de trabalho na visão de profissionais da saúde. Saúde e Sociedade, São Paulo, v. 17, n. 4, p. 151-160, 2008. http://dx.doi.org/10.1590/ S0104-12902008000400015

SEGNINI, M. P. Sofrimento e prazer no trabalho artístico em dança. 2010. 171 f. Dissertação (Mestrado em Cieências)Faculdade de Medicina, Universidade de São Paulo, São Paulo, 2010.
SILVA, J. A.; DALMASO, A. S. W. O Agente Comunitário de Saúde e suas atribuiçóes: os desafios para os processos de formação de recursos humanos em saúde. Interface: Comunicacao, Saude, Educacao, Botucatu, v. 6, n. 10, p. 75-94, fev. 2002.

TEIXEIRA, R. R. O acolhimento num serviço de saúde entendido como uma rede de conversaçóes. In: PINHEIRO, R.; DE MATTOS, R. A. (Orgs.). Construção da Integralidade: cotidiano, saberes e práticas em saúde. Rio de Janeiro: IMS-UERJ/ABRASCO, 2003. p. 89-111. Disponível em: <http://www.corposem.org/rizoma/ acolhiconversa.htm>. Acesso em: 25 out. 2011.

TRAD, L. A. B. Grupos focais: conceitos, procedimentos e reflexôes baseadas em experiências com o uso da técnica em pesquisas de saúde. Physis: Revista de Saúde Coletiva, Rio de Janeiro, v. 19, n. 3, p. 777-796, 2009. http://dx.doi. org/10.1590/S0103-73312009000300013

\section{Contribuição dos Autores}

As autoras trabalharam juntas em todas as etapas de produçáo do manuscrito. A primeira autora responsabilizou-se pela análise aprofundada de todo o material transcrito das gravações em áudios dos grupos focais e pela escrita final do texto.

\section{Notas}

${ }^{1} \mathrm{O}$ artigo apresenta parte dos resultados de uma pesquisa mais ampla: "Acolhimento e Acesso, consolidando a integralidade e $o$ direito à saúde: um estudo junto à rede de saúde de Paranaíba-MS”, aprovado pelo CONEP, número do protocolo: 1720 .

${ }^{2}$ É importante esclarecer que todos os trabalhadores das unidades eram convidados. O procedimento adotado foi solicitar uma reunião em cada unidade para apresentação do estudo e convite à participação com as assinaturas dos TCLE. Depois disso, sabendo-se quem e quantos eram os trabalhadores que aceitaram, decidia-se em conjunto pelo melhor horário para o grupo focal. Como geralmente os médicos não estavam nas reunióes, adotou-se o procedimento de procurá-los um a um para o convite, mas entre os seis contatados apenas um aceitou (embora na ocasião do grupo ele tenha iniciado a participação e a interrompido pouco tempo depois, justificando que iria para "um plantão"). Quanto aos outros médicos, respondiam que já não estariam na unidade naqueles horários (10 ou 16 horas), pois as consultas já teriam se encerrado e eles tinham que se dirigir para outros locais de trabalho.

${ }^{3} \mathrm{O}$ instrumento foi adaptado do roteiro utilizado no estudo de Souza et al. (2008). Acesso e acolhimento na atençấo básica: uma análise da percepção dos usuários e profissionais de saúde. Cad. Saúde Pública, Rio de Janeiro, 24 Sup1:S100-S110, 2008. Foi gentilmente disponibilizado pela autora, a quem agradecemos.

${ }^{4}$ A sigla ACS será utilizada para designar as falas dos agentes comunitários de saúde participantes dos grupos focais. 